\title{
METAIS PESADOS EM PLANTAS DE MILHO CULTIVADAS EM LATOSSOLOS REPETIDAMENTE TRATADOS COM BIOSSÓLIDO'
}

\author{
Ana Rosa Martins dos Anjos ${ }^{2,4 *}$; Maria Emilia Mattiazzo³ \\ ${ }_{2}^{2} P o ́ s-G r a d u a n d a$ em Solos e Nutrição de Plantas - USP/ESALQ. \\ ${ }^{3}$ Depto. de Ciências Exatas - USP/ESALQ, C.P. 9 - CEP: 13418-900 - Piracicaba, SP. \\ ${ }^{4}$ Bolsista FAPESP. \\ *Autor correspondente <armanjos@hotmail.com>
}

RESUMO: A presença de metais pesados em biossólidos é motivo de preocupação quando do uso agrícola desse resíduo em função da possibilidade de absorção desses metais pelas plantas crescendo nesse solo. A fitodisponibilidade de metais pesados, em solos repetidamente tratados com biossólido, foi avaliada num experimento em vasos de $0,5 \mathrm{~m}^{3}$, contendo LATOSSOLO AMARELO Distrófico (LAd) e LATOSSOLO VERMELHO Distrófico $(\mathrm{LVd})$. O experimento foi montado no delineamento em blocos ao acaso, com quatro tratamentos ( $L A d+l o d o, L A d, L V d+l o d o ~ e ~ L V d)$ e quatro repetições utilizando milho como planta teste. Incorporouse biossólido, proveniente da Estação de Tratamento de Esgotos ETE-SABESP-Barueri, São Paulo, na camada 0-0,2 m dos solos durante um período de até doze meses antes do plantio, numa quantidade total correspondente a $388 \mathrm{Mg} \mathrm{ha}^{-1}$, base seca. Antes da semeadura, os tratamentos testemunhas receberam calcário e adubação NPK, porém houve necessidade de adubação NPK nos tratamentos com biossólido, durante o desenvolvimento das plantas. As análises do tecido vegetal foram feitas por digestão nitro-perclórica, seguindo-se a quantificação dos metais por absorção atômica, nas seguintes partes da plantas: pendão, folha diagnose, folhas ao final do ciclo, colmo, bainha, grãos, sabugo e palha. As sucessivas aplicações do biossólido, em doses correspondentes a $78 \mathrm{Mg} \mathrm{ha}^{-1}$, não proporcionaram aumento de produtividade. Foi observado aumento dos teores de $\mathrm{Cu}$ e $\mathrm{Zn}$ nas plantas, evidenciando a disponibilidade desses metais adicionados via biossólido. Não foi observada disponibilidade de $\mathrm{Cd}, \mathrm{Cr}, \mathrm{Mn}, \mathrm{Ni}$ e $\mathrm{Pb}$ para as plantas de milho.

Palavras-chave: Zea mays, lodo de esgoto, $\mathrm{Cd}, \mathrm{Cr}, \mathrm{Cu}, \mathrm{Mn}, \mathrm{Ni}, \mathrm{Pb}$ e $\mathrm{Zn}$

\section{HEAVY METALS IN CORN GROWN ON OXISOLS CONTINUOUSLY AMENDED WITH BIOSOLID}

\begin{abstract}
The presence of heavy metals in sewage sludge amended soils can cause concern due to the possibility of the absorption of these metals by plants growing on these soils. The availability of $\mathrm{Cd}, \mathrm{Cr}, \mathrm{Cu}, \mathrm{Ni}$, $\mathrm{Pb}$ and $\mathrm{Zn}$ to corn plants in soils continuously treated with biosolids (sewage sludge) was evaluated by an experiment performed in $0.5 \mathrm{~m}^{3}$ pots with a dystrophic Typic Hapludox (LAd) and a dystrophic Rhodic Hapludox $(\mathrm{LVd})$. The adopted statistical design was random blocks with four treatments (LAd+sludge, LAd, LVd+sludge and LVd) and four replications. Biosolids from SABESP-Barueri treatment plant (São Paulo/Brazil) were applied every two months to the soils until one year before planting corn, totallizing $388 \mathrm{Mg} \mathrm{ha}^{-1}$. Before sowing the corn the control treatments (without sludge addition) received lime and NPK fertilizers. During crop growth soils with biosolids were also fertilized with NPK. At harvest corn plantlets were divided into: diagnose leaf, old leaves, stem, sheath, grains, corn cob and straw. This material was submitted to nitro-percloric digestion, and metals were quantified by conventional flame atomic absorption spectrophotometry. The successive biosolid applications, at rates of $78 \mathrm{Mg} \mathrm{ha}^{-1}$ each, did not increase corn yield, however plant availability was observed for $\mathrm{Cu}$ and $\mathrm{Zn}$. No plant availabilities for $\mathrm{Cd}, \mathrm{Cr}, \mathrm{Mn}, \mathrm{Ni}$ and $\mathrm{Pb}$ were observed.

Key words: Zea mays, sewage sludge, $\mathrm{Cd}, \mathrm{Cr}, \mathrm{Cu}, \mathrm{Mn}, \mathrm{Ni}, \mathrm{Pb}$ e $\mathrm{Zn}$
\end{abstract}

\section{INTRODUÇÃO}

A reciclagem de nutrientes contidos em lodo de esgoto (biossólido) pode ser feita através do seu uso em áreas agrícolas. Entretanto, metais pesados, particularmente $\mathrm{Cd}$, $\mathrm{Ni}$ e $\mathrm{Pb}$, presentes neste tipo de resíduo, são motivo de preocupação nesse uso em função da possibilidade de aumento de sua concentração em plantas desenvolvidas nessas áreas, podendo afetar seu crescimento e a saúde de animais e do homem, que se alimentam dessas plantas (Berti \& Jacobs, 1996). Boaretto et al. (1992) encontraram teores de $7,2 \mathrm{mg} \mathrm{kg}^{-1}$ de Ni nos grãos de feijão com aplicações acima de $10 \mathrm{Mg} \mathrm{ha}^{-1}$ de lodo de esgoto. Trabalhando com sorgo, André et al. (1994) observaram que as plantas que receberam $64 \mathrm{Mg} \mathrm{ha}^{-1}$ de lodo de esgoto apresentaram maior teor de $\mathrm{Cr}$, indicando que o lodo de esgoto contribuiu para aumentar o teor deste metal nos grãos de sorgo. Oliveira (1995) verificou que a adição de lodo de esgoto aos solos AQ e LV aumentou a concentração de $\mathrm{Cd}$, $\mathrm{Cu}, \mathrm{Cr}$, Ni e Zn nos mesmos, entretanto, evidências do aumento da disponibilidade desses metais, para plantas de milho, somente foram observadas na dose de 40,5 $\mathrm{Mg} \mathrm{ha}^{-1}$, base seca. 
A concentração de elementos químicos nas plantas depende da interação de um certo número de fatores, incluindo solo, espécie vegetal, estádio de maturação, rendimento, manejo da cultura e clima (McDowell et al., 1993). No entanto, o principal fator é o potencial de absorção, específico e geneticamente fixado para os diferentes nutrientes e diferentes espécies vegetais (Mengel \& Kirkby, 1987). Além disso, o acúmulo de metais pesados, é também muito variável de um determinado órgão para outro da planta (Porto, 1986).

Em função do exposto, os objetivos deste trabalho foram avaliar a fitodisponibilidade de metais pesados adicionados a solos via biossólido (lodo de esgoto) usando milho como planta teste.

\section{MATERIAL E MÉTODOS}

\section{Instalação do experimento}

$O$ experimento foi instalado em vasos com capacidade para $0,5 \mathrm{~m}^{3}$ de terra utilizando-se amostras de LATOSSOLO AMARELO Distrófico (LAd) e LATOSSOLO VERMELHO Distrófico (LVd), previamente tratados ou não com biossólido. $O$ delineamento estatístico adotado foi o de blocos ao acaso, com quatro tratamentos (LAd+lodo, LAd, LVd+lodo, LVd) e quatro repetições. Cada parcela foi composta por um vaso, preenchido a partir do fundo com: uma tela fina de malha de plástico, 0,04 $\mathrm{m}$ de pedra brita lavada $\mathrm{n}^{\circ} 1$, novamente a tela fina de plástico, 0,02 $\mathrm{m}$ de areia, $0,3 \mathrm{~m}$ de terra retirada da profundidade de 0,30-0,60 $\mathrm{m}$ e $0,3 \mathrm{~m}$ da profundidade de $0-0,3 \mathrm{~m}$. A quantidade de terra acondicionada nas parcelas experimentais (vasos), foi de $556 \mathrm{~kg}$ de LAd e $486 \mathrm{~kg}$ de LVd.

O biossólido utilizado no experimento foi proveniente da Estação de Tratamento de Esgotos da SABESP, localizada em Barueri - SP e foi aplicado aos solos até um ano antes do cultivo do milho, a cada dois meses, na profundidade de $0,2 \mathrm{~m}$ totalizando o equivalente a $388 \mathrm{Mg} \mathrm{ha}^{-1}$ de biossólido, base seca.

As características químicas, granulométricas, teores de óxidos de silício, ferro e alumínio removidos por ataque sulfúrico, teor total e disponível de metais presentes no solo por ocasião do plantio são apresentados nas TABELAS 1, 2 e 3. A metodologia adotada para essas análises foram as de Mehlich, (1984), Camargo et al.
(1986), Raij et al. (1987) e Amacher (1996). Na TABELA 1 são também apresentados os teores totais de $\mathrm{N}$, dos tratamentos determinados de acordo com Alcarde \& Chitolina (1991).

\section{Condução do experimento}

A disponibilidade dos metais presentes nos solos foi avaliada através de sua absorção por plantas de milho (Zea mays L.) híbrido duplo Cargill C-444, semeado em outubro de 1997, dois meses após a última aplicação de biossólido.

Dezenove dias antes do cultivo, os tratamentos LAd e LVd receberam calagem com calcário calcinado, para elevar a saturação por bases à $70 \%$. As quantidades utilizadas foram de 122 e $205 \mathrm{~g}$ por vaso de calcário respectivamente para LAd e LVd.

Por ocasião da semeadura foi aplicado, nos tratamentos testemunha, na linha de cultivo 30, 44, 33 e $4 \mathrm{~kg} \mathrm{ha}^{-1}$ respectivamente de N, P, K, e Zn. Os cálculos foram baseados nas sugestões de Raij \& Cantarella (1996), levando-se em consideração as análises de fertilidade dos solos (TABELA 1), teor de Cu e Zn extraídos do solo por Mehlich 3 (TABELA 3), e a área do vaso $\left(0,8825 \mathrm{~m}^{2}\right)$. Os fertilizantes minerais utilizados foram nitrato de amônio, superfosfato simples, cloreto de potássio e sulfato de zinco. Os tratamentos com biossólido receberam somente adubação potássica, correspondente a $33 \mathrm{~kg} \mathrm{ha}^{-1}$ de $\mathrm{K}$, pois os teores de $\mathrm{K}$ no solo classificaram-se como baixo no LAd e médio no LVd.

$\mathrm{Na}$ semeadura foram distribuídas três sementes de milho por cova, deixando-se uma planta por cova por ocasião do desbaste. Cada vaso comportou quatro covas num espaçamento de 0,50 × 0,30 m.

Aproximadamente duas semanas após a semeadura começaram a surgir sintomas de deficiência $P$ nas plantas de todos os tratamentos, bem como ocorreu o ataque de Spodoptera furgiperda. Assim, aplicou-se em cobertura nos tratamentos com biossólido o equivalente a $55 \mathrm{~kg} \mathrm{ha}^{-1}$ de $\mathrm{P}$ $\mathrm{e}$, nos tratamentos testemunha, $10 \mathrm{~kg} \mathrm{ha}^{-1}$ de P. Para combater a praga, pulverizou-se Lufenuron (40 mg i.a. $\mathrm{L}^{-1}$ de água).

Quando as plantas de milho apresentavam a quarta folha, 21 dias após a semeadura, foi realizada a primeira adubação mineral em cobertura com N (55 kg ha-1) nos tratamentos testemunha, junto com a adubação potássica em

TABELA 1 - Alguns atributos químicos da terra e condutividade elétrica dos tratamentos por ocasião do plantio(1). Valores médios de quatro repetições.

\begin{tabular}{|c|c|c|c|c|c|c|c|c|c|c|}
\hline \multirow[t]{2}{*}{ trat. } & \multirow[t]{2}{*}{ Condut. } & \multicolumn{2}{|c|}{$\mathrm{pH}$} & \multirow[t]{2}{*}{$\mathrm{N}$ total } & \multirow[t]{2}{*}{ C } & \multirow[t]{2}{*}{$P($ resina $)$} & \multirow[t]{2}{*}{$\mathrm{K}^{+}$} & \multirow[t]{2}{*}{$\mathrm{Ca}^{2+}$} & \multirow[t]{2}{*}{$\mathrm{Mg}^{2+}$} & \multirow[t]{2}{*}{$\mathrm{H}^{+}+\mathrm{Al}^{3+}$} \\
\hline & & água & $\mathrm{CaCl}_{2}$ & & & & & & & \\
\hline & $\mu \mathrm{S} \mathrm{cm}^{-1}$ & & & ------ g & 1 ------ & $\mathrm{mg} \mathrm{kg}^{-1}$ & ------- & ---- mm & $\mathrm{kg}^{-1}-$ & ---------.. \\
\hline LAd+lodo & 834 & 7,4 & 7,4 & 0,69 & 8,6 & 96,0 & 1,3 & 52,0 & 2,9 & 5,8 \\
\hline LAd & 50 & 5,4 & 4,8 & 0,34 & 4,4 & 7,4 & 0,7 & 8,8 & 3,3 & 26,8 \\
\hline LVd+lodo & 1.052 & 7,3 & 7,3 & 1,99 & 18,1 & 134,1 & 2,1 & 121,3 & 6,1 & 6,3 \\
\hline LVd & 102 & 5,1 & 4,9 & 0,98 & 10,5 & 12,6 & 1,3 & 20,7 & 4,9 & 47,3 \\
\hline
\end{tabular}

(1)47 dias após a última aplicação de biossólido. 
TABELA 2 - Granulometria e teores de óxidos de silício, ferro e alumínio dos solos utilizados na instalaçãodo experimento.

\begin{tabular}{|c|c|c|c|c|c|c|c|}
\hline Amostras & argila & $\begin{array}{c}\text { areia } \\
\text { grossa }\end{array}$ & $\begin{array}{c}\text { areia } \\
\text { fina }\end{array}$ & silte & $\mathrm{SiO}_{2}$ & $\mathrm{Fe}_{2} \mathrm{O}_{3}$ & $\mathrm{Al}_{2} \mathrm{O}_{3}$ \\
\hline & ------- & - & $-----g$ & $\mathrm{~g} \mathrm{~kg}^{-1}$ & & & \\
\hline $\begin{array}{l}\text { LVd } \\
0-0,30 \mathrm{~m}\end{array}$ & 593 & 90 & 208 & 109 & 184 & 126 & 192 \\
\hline $\begin{array}{l}\text { LVd } \\
0,30-0,60 \mathrm{~m}\end{array}$ & 616 & 67 & 209 & 108 & 193 & 128 & 206 \\
\hline $\begin{array}{l}\text { LAd } \\
0-0,30 \mathrm{~m}\end{array}$ & 151 & 326 & 492 & 31 & 59 & 16 & 45 \\
\hline $\begin{array}{l}\text { LAd } \\
0,30-0,60 \mathrm{~m}\end{array}$ & 161 & 304 & 528 & 7 & 68 & 17 & 50 \\
\hline
\end{tabular}

TABELA 3 - Teor total e disponível (Mehlich 3) de Cd, Cr, Cu, $\mathrm{Mn}, \mathrm{Ni}, \mathrm{Pb}$ e $\mathrm{Zn}$ nos solos dos tratamentos ${ }^{(1)}$.

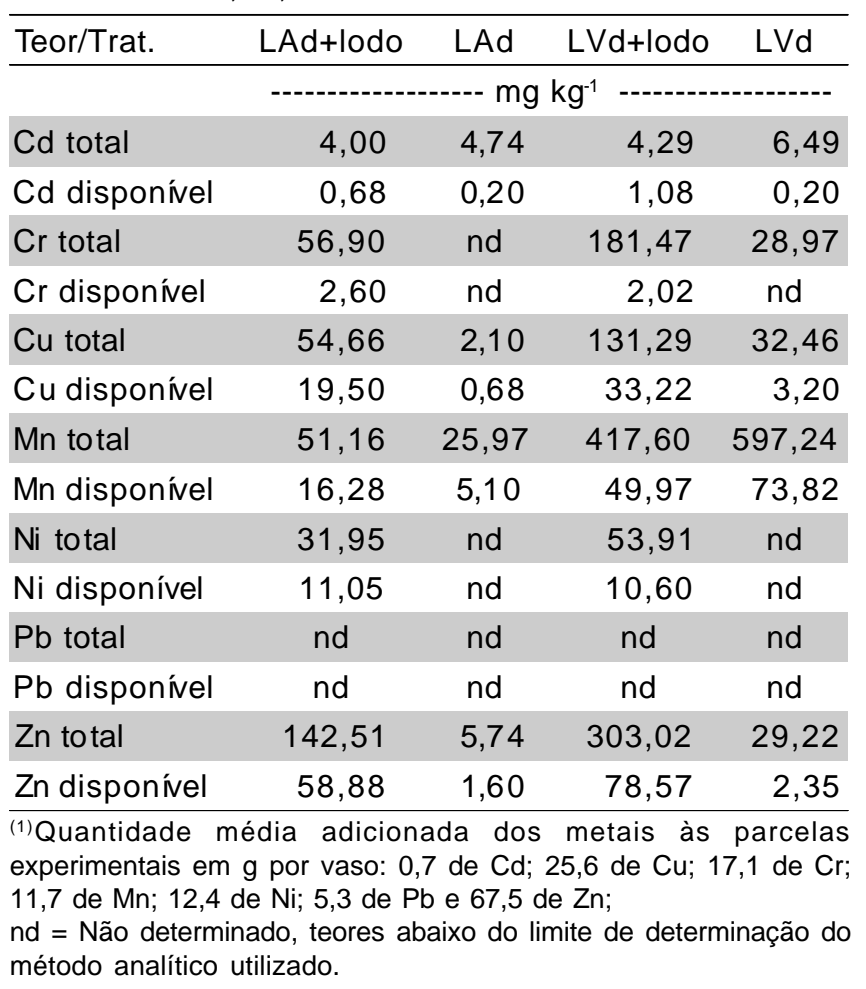

todos os tratamentos (33 kg ha $\left.{ }^{-1}\right)$. Como nessa ocasião as plantas dos tratamentos com biossólido mostravam sintomas de deficiência de $\mathrm{N}$, foi feita a aplicação de 85 $\mathrm{kg} \mathrm{ha}^{-1}$ de $\mathrm{N}$ em cobertura nesses tratamentos. A segunda adubação de $\mathrm{N}$ em cobertura, $55 \mathrm{~kg} \mathrm{ha}^{-1}$, foi realizada em todos os tratamentos, com as plantas de milho apresentando nove folhas, cinco semanas após a semeadura.

Durante o desenvolvimento da cultura de milho foi feita a coleta e armazenamento das folhas velhas. Nos meses de novembro de 1997, janeiro e fevereiro de 1998, foi necessário irrigar várias vezes a cultura com $8 \mathrm{~L}$ de água por vaso, devido à falta de chuva.
Quando $50 \%$ das plantas de milho apresentavam pendoamento, aproximadamente dois meses após a semeadura, foi coletado o terço médio da folha da base da espiga (folha diagnose-FD), de cada parcela experimental.

Decorridos 99 dias da semeadura foram colhidas as plantas dos tratamentos testemunha, por se encontrarem no ponto de maturidade fisiológica, enquanto que as plantas dos tratamentos com biossólido foram colhidas com 119 dias. As plantas foram separadas em pendão, folhas (incluindo-se as folhas velhas retiradas $\mathrm{e}$ armazenadas durante o período de crescimento das plantas), colmo, bainha, grãos, sabugo e palha que envolve a espiga. Os pendões, grãos e sabugos foram postos diretamente para secar em estufa a $60^{\circ} \mathrm{C}$ até peso constante, enquanto que os demais materiais vegetais, inclusive as folhas diagnose, colhidas anteriormente, foram lavados com água corrente, solução de $\mathrm{HCl} 0,1 \mathrm{~mol} \mathrm{~L}^{-1} \mathrm{e}$ com água destilada, sendo postos para secar em estufa. Posteriormente todos esses materiais vegetais foram submetidos a digestão nitro-perclórica (Tedesco et al., 1995), sendo determinados, nos extratos, os teores dos metais $\mathrm{Cd}, \mathrm{Cu}, \mathrm{Cr}, \mathrm{Ni}, \mathrm{Pb}, \mathrm{Zn}$ e $\mathrm{Mn}$ por espectrofotometria de absorção atômica convencional, com chama ar/acetileno.

\section{Tratamento estatístico dos resultados}

As análises estatísticas das variáveis matéria seca e teor de metais nas diversas partes das plantas, foram realizadas considerando-se o delineamento em blocos casualizados, com quatro tratamentos, quatro repetições e média de quatro plantas por parcela (Steel \& Torrie, 1960; Gomes, 1987).

Sempre que se detectou diferença significativa, pelo teste $F$, entre os tratamentos, procedeu-se ao desdobramento dos graus de liberdade em contrastes ortogonais.

A análise exploratória de dados foi realizada através de análise gráfica dos resíduos e teste de homogeneidade de variâncias, utilizando-se o teste de Levene (Souza, 1998). As seguintes variáveis necessitaram transformações (Hoaglin et al., 1992): Teores de Cu na bainha e colmo: log $(Y)$; $M n$ na FD: $\log (Y)$; Quantidade absorvida de Cu no colmo e palha: $\log (Y)$; Mn no sabugo: $\sqrt{Y}$; Zn na bainha, colmo e palha: $\log (Y)$; Zn na FD: $1 / \sqrt{Y}$

\section{RESULTADOS E DISCUSSÃO}

\section{METAIS PESADOS}

Os resultados referentes aos metais $\mathrm{Cd}, \mathrm{Cr}$ (com exceção do contido no sabugo), $\mathrm{Ni}$ e $\mathrm{Pb}$ nas diversas partes das plantas de milho não serão apresentados, pois estiveram abaixo do limite de determinação (nd) do método analítico empregado, embora tenham sido incorporadas aos tratamentos com biossólido, nas quantidades de 3,54 e $23 \mathrm{mg} \mathrm{kg}^{-1}$ respectivamente de $\mathrm{Cd}$, Ni e Pb no LAd e 4 , 64 e $27 \mathrm{mg} \mathrm{kg}^{-1}$ no LVd. 


\section{Crômio}

Pela técnica dos contrastes ortogonais, encontraram-se para a variável teor no sabugo diferenças entre os tratamentos testemunha, o que indica a existência de diferenças na ocorrência natural do elemento nos solos. As plantas de milho que se desenvolveram no tratamento LVd apresentaram os maiores teores médios de $\mathrm{Cr}$ no sabugo $\left(1,85 \mathrm{mg} \mathrm{kg}^{-1}\right)$, sendo a quantidade média do elemento removida do solo e presente nessa parte da planta de $0,04 \mathrm{mg}$ por vaso (TABELA 4).

A não constatação do aumento do teor $\mathrm{Cr}$ em outras partes das plantas, apesar de se ter aplicado, via biossólido, 75 e $88 \mathrm{mg} \mathrm{kg}^{-1}$ de $\mathrm{Cr}$, respectivamente, no LAd e LVd, diverge do que foi observado por André et al. (1994) em sorgo granífero, Oliveira (1995) e Pierrisnard (1996) em milho. Ritter \& Eastburn (1978) após aplicarem 0, 22, 45 e $90 \mathrm{Mg} \mathrm{ha}^{-1}$ de lodo de esgoto, base seca, em um solo franco siltoso, constataram concentrações normais de $\mathrm{Cr}$ nos grãos de milho e nos colmos $\left(<1,0 \mathrm{mg} \mathrm{kg}^{-1}\right.$ de $\mathrm{Cr}$ no grão e de $<1,0-2,0 \mathrm{mg} \mathrm{kg}^{-1}$ de $\mathrm{Cr}$ nos colmos). Após três aplicações anuais de lodo de esgoto em um solo franco siltoso, que totalizou aplicações acumuladas de 0, 60, 120 e $180 \mathrm{Mg} \mathrm{ha}^{-1}$ na base seca. Bidwell \& Dowdy (1987) observaram que as concentrações de $\mathrm{Cr}$, nos colmos e grãos, oscilaram anualmente, não sendo preditas pelas doses de lodo de esgoto aplicadas.

\section{Cobre}

As plantas que se desenvolveram nos tratamentos com biossólido, independentemente do tipo de solo, apresentaram maiores teores, em todas as partes analisadas, do que as plantas desenvolvidas nos tratamentos testemunha (TABELA 4), indicando que o $\mathrm{Cu}$ adicionado via biossólido contribuiu para aumentar os teores desse elemento nas diversas partes da planta de milho. Tal comportamento também foi constatado por Ritter \& Eastburn (1978), Reddy et al. (1989), Al-Jaloud et al. (1995), Oliveira (1995), Pierrisnard (1996) e Logan et al. (1997), o que evidencia a disponibilidade do elemento aplicado via biossólido.

Os teores médios de $\mathrm{Cu}$ encontrados na folha diagnose (FD) das plantas dos tratamentos com e sem biossólido (TABELA 4) encontram-se dentro do intervalo considerado adequado de $6-20 \mathrm{mg} \mathrm{kg}^{-1}$, relatado por Malavolta et al. (1989) e Raij et al. (1996).

No presente trabalho foi encontrado, nos tratamentos com biossólido, aproximadamente, $3 \mathrm{mg} \mathrm{kg}^{-1}$ de Cu nos grãos e $5 \mathrm{mg} \mathrm{kg}^{-1}$ de Cu nos colmos da planta de milho. Estes resultados foram próximos aos obtidos por Reddy et al. (1989), respectivamente, 2 e $7 \mathrm{mg} \mathrm{kg}^{-1}$, ao aplicar $200 \mathrm{Mg} \mathrm{ha}^{-1}$ de lodo de esgoto base seca, em um solo franco arenoso. Conforme os autores, as concentrações de Cu nos grãos de milho encontravam-se dentro da faixa considerada normal para a cultura. Rappaport et al. (1988) também comentam que, ao aplicar doses crescentes de lodo de esgoto (de 0 à $210 \mathrm{Mg} \mathrm{ha}^{-1}$ na base seca), em três solos de texturas distintas, as con- centrações de Cu nos grãos de milho e nas folhas da base da espiga (folhas diagnose) de todos os tratamentos mantiveram-se dentro da faixa considerada adequada. Na maior dose aplicada (210 $\left.\mathrm{Mg} \mathrm{ha}^{-1}\right)$ os valores médios foram de 5 e $8 \mathrm{mg} \mathrm{kg}^{-1}$ respectivamente para grãos e folha diagnose.

Os teores médios de $\mathrm{Cu}$ em todas as partes da planta dos tratamentos testemunha (TABELA 4), com exceção dos grãos, foram maiores nas desenvolvidas no $\mathrm{LVd}$, o que pode ser atribuído ao fato desse solo apresentar, originalmente, maior teor deste elemento $(2,1$ $\mathrm{mg} \mathrm{dm}^{-3}$ de terra) do que o LAd (0,3 $\mathrm{mg} \mathrm{dm}^{-3}$ de terra).

Quanto à ocorrência desse metal nas partes das plantas de milho, verificou-se que, tanto na testemunha como nos tratamentos com biossólido, os maiores teores de $\mathrm{Cu}$ foram encontrados nas folhas (TABELA 4), incluindo folha diagnose (FD) e folha ao final do ciclo da cultura (FF), enquanto que concentrações menores e semelhantes foram encontradas nos grãos.

\section{Manganês}

Os teores de Mn, encontrados na bainha e no colmo, nos tratamentos com biossólido foram menores (TABELA 4). Nas demais partes avaliadas não se observaram diferenças entre tratamentos.

Com relação a ocorrência desse metal em plantas de milho, constatou-se que, os maiores teores foram encontrados na folha ao final do ciclo (FF), seguidos pela bainha e folha diagnose (FD) (TABELA 4). Assim, o Mn além de tender a se acumular nas folhas, também tende a se acumular especificamente na bainha do milho.

\section{Zinco}

Os teores de $\mathrm{Zn}$ encontrados, em todas as partes das plantas de milho, nos tratamentos com biossólido foram maiores, o que evidencia que a adição do resíduo promoveu maior disponibilidade do elemento (TABELA 4).

Considerando-se que o aumento da quantidade de $\mathrm{Zn}$ absorvida pelas plantas foi devida ao biossólido, podese calcular que a quantidade absorvida deste elemento representou $0,01 \%$ da adicionada em ambos os tratamentos com o resíduo. Este comportamento está de acordo com o observado por Chang et al. (1987) que comentam que, as quantidades de metais absorvidas pelas plantas, em áreas que receberam lodo de esgoto, são pequenas e geralmente inferiores a $1 \%$, da quantidade fornecida pelo resíduo.

Estudando, durante um período de seis anos, a disponibilidade de Cd e Zn para a cultura de milho, ao final de três aplicações anuais de lodo de esgoto, em um solo franco siltoso, totalizando aplicações acumuladas de 0,60 , 120 e $180 \mathrm{Mg} \mathrm{ha}^{-1}$ de lodo na base seca, Bidwell \& Dowdy (1987) também observaram aumento significativo nos teores de Zn, nos colmos e grãos, com o teor nos colmos aumentando linearmente com as aplicações. Reddy et al (1989) também constataram o aumento na concentração 
TABELA 4 - Teor e quantidade absorvida de metais encontrados nas diversas partes da planta de milho em função das aplicações de biossólido.

\begin{tabular}{|c|c|c|c|c|c|c|c|c|}
\hline \multirow[t]{3}{*}{ Partes } & \multicolumn{2}{|c|}{ LAd+lodo } & \multicolumn{2}{|c|}{ LAd } & \multicolumn{2}{|c|}{ LVd+lodo } & \multicolumn{2}{|c|}{ LVd } \\
\hline & Teor & Quant. abs. & Teor & Quant. abs. & Teor & Quant. abs. & Teor & Quant. abs. \\
\hline & $\mathrm{mg} \mathrm{kg}^{-1}$ & $\mathrm{mg}$ por vaso & $\mathrm{mg} \mathrm{kg}^{-1}$ & $\mathrm{mg}$ por vaso & $\mathrm{mg} \mathrm{kg}^{-1}$ & mg por vaso & $\mathrm{mg} \mathrm{kg}^{-1}$ & $\mathrm{mg}$ por vaso \\
\hline & \multicolumn{8}{|c|}{$\mathrm{Cr}$} \\
\hline \multirow[t]{2}{*}{$\begin{array}{l}\text { Sabugo } \\
\text { CV\%=35,3 }\end{array}$} & 1,17 & 0,03 & 0,94 & 0,02 & 1,33 & 0,02 & 1,85 & 0,04 \\
\hline & \multicolumn{8}{|c|}{$\mathrm{Cu}$} \\
\hline $\begin{array}{l}\text { Grão } \\
\text { CV\%=28,5 }\end{array}$ & 2,76 & 0,27 & 2,37 & 0,20 & 2,80 & 0,18 & 2,46 & 0,20 \\
\hline $\begin{array}{l}\text { Bainha } \\
\text { CV\%=13,9 }\end{array}$ & 5,44 & 0,15 & 2,09 & 0,05 & 6,01 & 0,15 & 2,65 & 0,06 \\
\hline $\begin{array}{l}\text { Colmo } \\
\text { CV\%=14,4 }\end{array}$ & 4,51 & 0,41 & 1,21 & 0,09 & 5,19 & 0,51 & 2,30 & 0,14 \\
\hline $\begin{array}{l}\text { Palha } \\
\text { CV\%=22,0 }\end{array}$ & 5,51 & 0,01 & 1,82 & 0,002 & 5,52 & 0,01 & 2,95 & 0,003 \\
\hline $\begin{array}{l}\text { Sabugo } \\
\text { CV\% }=27,7\end{array}$ & 4,18 & 0,08 & 2,04 & 0,05 & 4,44 & 0,07 & 3,39 & 0,07 \\
\hline $\begin{array}{l}\text { FD } \\
\text { CV\%=11,3 }\end{array}$ & 14,26 & 0,03 & 6,36 & 0,01 & 14,73 & 0,03 & 12,02 & 0,02 \\
\hline \multirow[t]{2}{*}{$C V \%=14,8$} & 10,32 & 0,50 & 4,32 & 0,18 & 13,12 & 0,58 & 8,81 & 0,39 \\
\hline & \multicolumn{8}{|c|}{$\mathrm{Mn}$} \\
\hline $\begin{array}{l}\text { Grão } \\
\text { CV\%=23,2 }\end{array}$ & 9,30 & 0,91 & 9,29 & 0,79 & 10,47 & 0,68 & 10,26 & 0,80 \\
\hline $\begin{array}{l}\text { Bainha } \\
\text { CV\%=29,8 }\end{array}$ & 23,88 & 0,64 & 73,54 & 1,78 & 63,44 & 1,58 & 107,88 & 2,49 \\
\hline $\begin{array}{l}\text { Colmo } \\
\text { CV\%=23,6 }\end{array}$ & 3,53 & 0,34 & 9,73 & 0,70 & 8,34 & 0,84 & 13,64 & 0,87 \\
\hline $\begin{array}{l}\text { Palha } \\
\text { CV\%=14,7 }\end{array}$ & 7,60 & 0,19 & 10,79 & 0,24 & 16,26 & 0,41 & 16,52 & 0,32 \\
\hline $\begin{array}{l}\text { Sabugo } \\
\text { CV\%=36,2 }\end{array}$ & 7,19 & 0,13 & 7,58 & 0,18 & 11,96 & 0,18 & 9,35 & 0,19 \\
\hline $\begin{array}{l}\text { FD } \\
\text { CV\% } \%=4,6\end{array}$ & 22,79 & 0,05 & 27,46 & 0,04 & 64,71 & 0,13 & 50,16 & 0,08 \\
\hline \multirow[t]{2}{*}{$\begin{array}{l}\mathrm{FF} \\
\mathrm{CV} \%=26,5\end{array}$} & 24,86 & 1,23 & 44,01 & 1,83 & 119,92 & 5,33 & 92,99 & 4,11 \\
\hline & \multicolumn{8}{|c|}{$\mathrm{Zn}$} \\
\hline $\begin{array}{l}\text { Grão } \\
\text { CV\%=21,5 }\end{array}$ & 53,23 & 5,28 & 42,53 & 3,59 & 45,54 & 3,04 & 38,17 & 3,00 \\
\hline $\begin{array}{l}\text { Bainha } \\
\text { CV\%=9,5 }\end{array}$ & 27,24 & 0,73 & 9,32 & 0,23 & 21,73 & 0,55 & 4,97 & 0,11 \\
\hline $\begin{array}{l}\text { Colmo } \\
\text { CV\%=12,1 }\end{array}$ & 41,38 & 3,85 & 10,70 & 0,76 & 35,89 & 3,67 & 8,16 & 0,51 \\
\hline $\begin{array}{l}\text { Palha } \\
\text { CV\%=7,6 }\end{array}$ & 74,72 & 1,86 & 17,11 & 0,39 & 55,91 & 1,36 & 10,30 & 0,20 \\
\hline $\begin{array}{l}\text { Sabugo } \\
\text { CV\% }=57,7\end{array}$ & 85,69 & 1,68 & 16,66 & 0,40 & 93,86 & 1,36 & 14,05 & 0,29 \\
\hline $\begin{array}{l}\text { FD } \\
\text { CV\% }=6,0\end{array}$ & 33,43 & 0,08 & 17,91 & 0,03 & 28,36 & 0,06 & 14,99 & 0,02 \\
\hline $\begin{array}{l}\mathrm{FF} \\
\mathrm{CV} \%=29,0\end{array}$ & 40,59 & 2,02 & 11,55 & 0,49 & 37,46 & 1,69 & 10,09 & 0,45 \\
\hline
\end{tabular}

$\mathrm{CV} \%=$ Coeficiente de variação referentes apenas aos teores de metais.

de $\mathrm{Zn}$ em folhas e colmos de plantas de milho, em função da adição de lodo de esgoto em doses de 25, 50 e 100 $\mathrm{Mg} \mathrm{ha}^{-1}$ na base seca, entretanto não observaram alterações na concentração desse elemento nos grãos.

Estudo conduzido por Logan et al. (1997) em um solo franco argiloso, ao qual foi incorporado biossólido na profundidade de $0,15 \mathrm{~m}$, em doses de $0,7,5,15,30$, $60,90,120,150,188,225$ e $300 \mathrm{Mg}^{-1}$ na base seca, mostrou que as plantas de milho cultivadas apresentaram teor de $\mathrm{Zn}$ significativamente maior nas folhas diagnose, aumento esse que foi linear com as doses aplicadas. 
Os teores médios de $\mathrm{Zn}$ encontrados nas plantas cultivadas no LAd foram maiores do que no LVd, independentemente de se aplicar ou não biossólido. Essa maior disponibilidade de Zn verificada no LAd, é contrária a observada para os outros metais estudados, que apresentaram, de maneira geral, maiores teores nas plantas cultivadas no LVd. A menor absorção, conseqüência da menor disponibilidade de Zn observadas nas plantas cultivadas no LVd pode estar relacionada à maior capacidade de retenção desse elemento, sendo que muitos autores têm encontrado relações positivas e significativas entre os teores de argila e óxidos e hidróxidos de $\mathrm{Fe}$ e Al, com a adsorção de Zn (Kalbasi et al., 1978; Pombo \& Klamt, 1986).

Os teores médios de $\mathrm{Zn}$ observados na folha diagnose (FD) das plantas de milho (TABELA 4), de todos os tratamentos, encontram-se dentro do intervalo de 15$100 \mathrm{mg} \mathrm{kg}^{-1}$ considerado adequado por Raij et al. (1996). Entretanto, se for considerado o intervalo de 15$50 \mathrm{mg} \mathrm{kg}^{-1}$, proposto por Malavolta et al. (1989), os teores obtidos nos tratamentos com biossólido se encontram bem acima dessa faixa. Isto sugere que plantas de milho cultivado em solos tratados com biossólido, durante vários anos, podem apresentar problemas relacionados com fitotoxicidade. Essas observações também foram feitas por Oliveira (1995).

Ao avaliar a disponibilidade de metais em solos tratados com biossólido, Rappaport et al. (1988) verificaram que, apesar da aplicação de $\mathrm{Zn}$, via biossólido, exceder o limite estabelecido pelo USEPA, não se observou fitotoxicidade deste elemento às plantas de milho, nos diversos solos estudados.

A fitotoxicidade dos metais pesados em áreas que receberam, durante um período de oito anos, repetidas aplicações de biossólido foi estudada por Berti \& Jacobs (1996). Os autores observaram que o rendimento do milho foi reduzido em um ou mais tratamentos onde o biossólido foi aplicado em taxas de 240,690 e $780 \mathrm{Mg} \mathrm{ha}^{-1}$, atribuindo essa redução à concentração fitotóxicas de metais, provavelmente $\mathrm{Zn}$ e $\mathrm{Ni}$, uma vez que através de extração seqüencial constataram que aqueles metais encontravam-se em frações potencialmente disponíveis a absorção pelas plantas (solúvel em água, trocável e solúvel em ácido).

No que se refere ao teor de $\mathrm{Zn}$ nas partes da planta constatou-se que, maiores teores nos tratamentos com biossólidos, foram: sabugo>palha>grão. Entretanto, quando se considera a quantidade absorvida, pode-se observar o acúmulo do elemento nos grãos.

\section{PRODUTIVIDADE}

A produtividade das plantas de milho foi avaliada pelo peso dos grãos, corrigindo-se a umidade para $13 \%$. Pela técnica dos contrastes ortogonais, verificou-se que não houve diferença significativa na comparação entre produtividade no tratamento com biossólido e com adubação convencional (testemunha). Convém salientar que a adição de $\mathrm{N}$ e $\mathrm{P}$ através de fertilizantes foi feita também nos tratamentos com biossólido, devido a constatação de sintomas de deficiência destes macronutrientes, que desapareceram após a adubação. A quantidade de $\mathrm{N}$ e $\mathrm{P}$ adicionada via biossólido foi respectivamente de 4,0 e 3,4 $\mathrm{Mg} \mathrm{ha}^{-1}$, o que elevou o teor de $\mathrm{N}$ total e $\mathrm{P}$ nesses tratamentos (TABELA 1). Mattiazzo et al. (1998) estimaram que a carga orgânica do lodo de esgoto (biossólido), aplicado numa dose de $37,7 \mathrm{Mg} \mathrm{ha}^{-1}$ em base seca, apresentava-se $30 \%$ degradada aos 60 dias de incubação. Supondo-se que a essa taxa de degradação correspondesse $20 \%$ de $\mathrm{N}$ disponível para as plantas (Raij, 1998), ter-se-ia um total de $779 \mathrm{~kg} \mathrm{ha}^{-1}$ deste elemento, mais que suficiente para atender a cultura. Na pior das hipóteses, se fosse considerada somente a aplicação de biossólido que antecedeu o cultivo do milho e que a lixiviação de $\mathrm{N}$ como nitratos tenha sido de $7 \% \mathrm{em}$ relação à quantidade adicionada (Anjos, 1999), ter-se-ia $144 \mathrm{~kg} \mathrm{ha}^{-1}$ de $\mathrm{N}$, o que ainda seria suficiente para nutrir a cultura, de acordo com Raij \& Cantarella (1996). Silva (1995) também verificou que quando se aplicou o biossólido sem suplementação de N, houve um ligeiro amarelecimento das folhas mais velhas da cana-de-açúcar, característico da deficiência de N. Essas constatações indicam que a questão da taxa de degradação do material orgânico do biossólido e a taxa de mineralização do $\mathrm{N}$ é um assunto que necessita de mais estudos.

Ainda com relação a quantidade de grãos produzida, e considerando-se apenas os tratamentos com biossólido (Figura 1 e TABELA 5), pode-se verificar que a maior produtividade foi obtida no LAd+lodo.

\section{Produtividade $\mathrm{x}$ Metais na planta}

Ao se correlacionar a produtividade e os teores (ou quantidades absorvidas) de $\mathrm{N}$ e dos metais $\mathrm{Cr}, \mathrm{Cu}, \mathrm{Mn}$ e $\mathrm{Zn}$ encontrados nas diversas partes da planta, levandose em consideração todos os tratamentos, somente os tratamentos LAd+lodo e somente os tratamentos $L V d+l o d o$, observou-se que os coeficientes obtidos indicaram não haver correlação, à exceção do $\mathrm{Zn}$ ao se considerar somente os dados do tratamento $\mathrm{LVd}$ +lodo $(\mathrm{r}$ $=-0,73^{* *}$ ). Desta forma, a menor produtividade constatada nesse tratamento (Figura 1 e TABELA 5) pode estar relacionada, além da salinidade observada no solo (TABELA 1), à absorção de maiores quantidades de $\mathrm{Zn}$ pelas plantas, nos tratamentos com biossólido, que se encontravam bem acima da faixa considerada adequada para a cultura, de acordo com Malavolta et al. (1989).

TABELA 5 - Produtividade das plantas de milho em função das aplicações de biossólido.

\begin{tabular}{lcccc}
\hline & LAd+lodo & LAd & LVd+lodo & LVd \\
\cline { 2 - 5 } & --1 & $---\mathrm{kg} \mathrm{ha}^{-1}$ & - \\
Produtividade & 4.534 & 4.381 & 2.828 & 4.066 \\
\hline
\end{tabular}




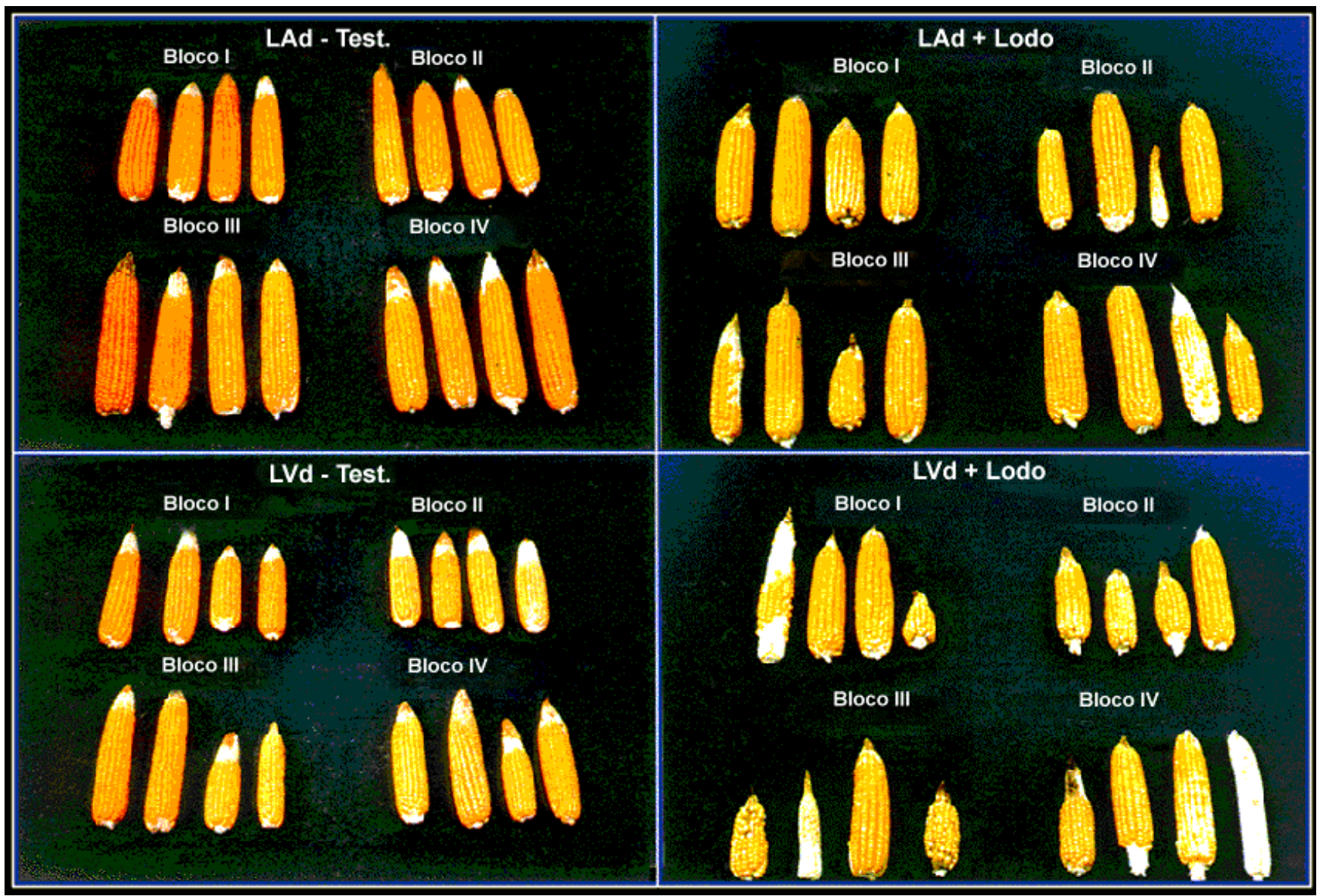

Figura 1 - Aspecto geral das espigas produzidas em cada tratamento e em cada bloco.

\section{AGRADECIMENTOS}

À FAPESP pelos recursos concedidos para a realização do projeto e aos técnicos de laboratório Lenita M.P. e Oliveira e Carlos Rubini Jr. pelo auxílio nas análises executadas.

\section{REFERÊNCIAS BIBLIOGRÁFICAS}

ALCARDE, J.C.; CHITOLINA, J.C. Determinação do nitrogênio total em solos pelo método da liga de Raney. Revista de Agricultura, v.66, p.97-106, 1991.

AL-JALOUD, A.A.; HUSSAIN, G.; AL-SAATI, A.J.; KARIMULLA, $S$. Effect of wastewater irrigation on mineral composition of corn and sorghum plants in a pot experiment. Journal of Plant Nutrition, v.18, p.1677-1692, 1995.

AMACHER, , M.C. Nickel, Cadmium, and Lead. In: SPARKS, D.L. ; PAGE, A.L.; HELMKE, P.A.; LOEPPERT, R.H.; SOLTANPOUR, P.N.; TABATABAI, M.A.; JOHNSTON, C.T.; SUMNER, M.E. (ED.) Methods of soil analysis: chemical methods. Madison: Soil Science Society of America, 1996. cap. 28, pt.3, p.739-768.

ANDRÉ, E.M.; MELO, W.J.; MELO, G.M.P.; CHELLI, R.A.; LEITE, S.A.S. Metais pesados em sorgo granífero [Sorghum bicolor (L.) Moench] adubado com lodo de esgoto. In: REUNIÃO BRASILEIRA DE FERTILIDADE DO SOLO E NUTRIÇÃO DE PLANTAS, Petrolina, 1994. Anais. Petrolina: EMBRAPA, CPATSA; SBCS, 1994. p.159-161.
ANJOS, A.R.M. dos. Lixiviação de espécies químicas em latossolos sucessivamente tratados com biossólido e disponibilidade de metais pesados para plantas de milho. Piracicaba, 1999. 191p. Tese (Doutorado) - Escola Superior de Agricultura "Luiz de Queiroz", Universidade de São Paulo.

BERTI, W.R.; JACOBS, L.W. Chemistry and phytotoxicity of soil trace elements from repeated sewage sludge applications. Journal of Environmental Quality, v.25, p.1025-1032, 1996.

BIDWELL, A.M.; DOWDY, R.H. Cadmium and zinc availability to corn following termination of sewage sludge applications Journal of Environmental Quality, v.16, p.438-442, 1987.

BOARETTO, R.S.; MURAOKA, T.; NAKAGAWA, J.; CHITOLINA, J.C. Níquel e cádmio em grãos de feijão produzidos em solo adubado com lodo de esgoto. In: REUNIÃO BRASILEIRA DE FERTILIDADE DO SOLO E NUTRIÇÃO DE PLANTAS, 20., Piracicaba, 1992. Adubação, produtividade, ecologia anais. Piracicaba: SBCS, 1992. p.400-401.

CAMARGO, O.A. de; MONIZ, A.C.; JORGE, J.A.; VALADARES, J.M.A.S. Métodos de análise química, mineralógica e física de solos do Instituto Agronômico de Campinas. Campinas: Instituto Agronômico de Campinas, 1986. 94p. (Boletim Técnico, 106).

CHANG, A.C.; HINESLY, T.D.; BATES, T.E.; DONER, H.E.; DOWDY, R.H.; RYAN, J.A. Effects of long-term sludge application on accumulation of trace elements by crops. In: PAGE, A.L.; LOGAN, T.G.; RYAN, J.A. Land application of sludge. Chelsea: Lewis Publishers, 1987. cap.4, p.53-66.

GOMES, F.P. Curso de estatística experimental. 12.ed. Piracicaba: Livraria Nobel, 1987. 466p. 
HOAGLIN, D.C.; MOSTELLER, F.; TUKEY, J.W. Análise exploratória de dados: técnicas robustas. Lisboa: John Wiley, 1992. 446p.

KALBASI, M.; RACZ, G.J.; LOEWEN-RUDGERS, L.A. Mechanism of zinc adsorption by iron and aluminum oxides. Soil Science, v.125, p.146-150, 1978.

LOGAN, T.J.; LINDSAY, B.J.; GOINS, L.E.; RYAN, J.A. Field assessment of sludge metal bioavailability to crops: sludge rate response. Journal of Environmental Quality, v.26, p.534-550, 1997.

McDOWELL, L.R.; CONRAD, J.H.; HEMBRY, F.G. Minerals for grazing ruminants in tropical regions. 2.ed. Gainesville: University of Florida, 1993. 77p.

MALAVOLTA, E.; VITTI, G.C.; OLIVEIRA, S.A. Avaliação do estado nutricional de plantas: princípios e aplicações. Piracicaba: Potafós, 1989. 201p.

MATTIAZZO, M.E.; BARRETTO, M.C.V.; RODELLA, A.A. Organic matter kinetics mineralization in soils amended with four different organic wates (compact disc). In: CONGRESS MONDIAL DE SCIENCE DU SOL, 16., Montpellier, 1998. Actes. Montpellier: ISSS, 1998.

MEHLICH, A. Mehlich $n^{\circ} 3$ soil test extractant: a modification of Mehlich $n^{\circ} 2$. Communications in Soil Science and Plant Analysis, v.15, p.1409-1416, 1984.

MENGEL, K.; KIRKBY, E.A. Principles of plant nutrition. 4.ed. Bern: International Potash Institute, 1987. 687p.

OLIVEIRA, F.C. Metais pesados e formas nitrogenadas em solos tratados com lodo de esgoto. Piracicaba, 1995. 90p. Dissertação (Mestrado) - Escola Superior de Agricultura "Luiz de Queiroz", Universidade de São Paulo.

PIERRISNARD, F. Impact de l'amendement des boues residuaires de la ville de Marseille sur des sols a vocation agricole: comportement du $\mathrm{Cd}, \mathrm{Cr}, \mathrm{Cu}, \mathrm{Ni}, \mathrm{Pb}, \mathrm{Zn}$, des hydrocarbures et des composes polaires. Marseille, 1996. 408p. These (Docteur) - Facolte des Sciences et Techniques de Saint-Jerome, Universite de Droit d'Ecomonie et des Sciences d'AIX-MARSEILLE.

POMBO, L.C.A.; KLAMT, E. Adsorção de zinco e cobre de dois solos do Estado do Rio Grande do Sul. Revista Brasileira de Ciência do Solo, v.10, p.191-194, 1986.

PORTO, M.L. Vegetação metalófita e o desenvolvimento do setor mineral. In: SIMPÓSIO DO TRÓPICO ÚMIDO, Belém, 1986. Anais. Belém: EMBRAPA, CPATU, 1986. p.171-183.

RAIJ, B. van. Uso agrícola de biossólidos. In: SEMINÁRIO SOBRE GERENCIAMENTO DE BIOSSÓLIDOS DO MERCOSUL, 1., Curitiba, 1998. Anais. Curitiba: SANEPAR; ABEAS, 1998. p.147-151.
RAIJ, B. van; CANTARELLA, H. Milho para grãos e silagem. In: RAIJ, B. van; CANTARELLA, H.; QUAGGIO, J.A.; FURLANI, A.M.C. (Ed.) Recomendações de adubação e calagem para - Estado de São Paulo. 2.ed. Campinas: Instituto Agronômico, 1996. p.56-59. (Boletim Técnico, 100).

RAIJ, B. van; CANTARELLA, H.; CAMARGO, C.E.O. Cereais. In: RAIJ, B. van; CANTARELLA, H; QUAGGIO, J.A.; FURLAN, A.M.C. (Ed.) Recomendações para adubação e calagem no Estado de São Paulo. 2.ed. Campinas:Instituto Agronômico, 1996. p.45-49. (Boletim Técnico, 100).

RAIJ, B. van; QUAGGIO, J.A; CANTARELLA, H.; FERREIRA, M.E.; LOPES, A.S.; BATAGLIA, O.C. Análise química do solo para fins de fertilidade. Campinas: Fundação Cargill, 1987. 170p.

RAPPAPORT, B.D.; MARTENS, D.C.; RENEAU JR., R.B.; SIMPSON, T.W. Metal availability in sludge-amended soils with elevated metals levels. Journal of Environmental Quality, v.17, p.42-47, 1988.

REDDY, M.R.; LAMECK, D.; REZANIA, M.E. Uptake and distribuition of copper and zinc by soybean and corn from soil treated with sewage sludge. Plant and Soil, v.113, p.271-274, 1989.

RITTER, W.F.; EASTBURN, R.P. The uptake of heavy metals from sewage sludge applied to land by corn and soybeans. Communications in Soil Science and Plant Analysis, v.9, p.799-811, 1978.

SILVA, F.C. da. Uso agronômico de lodo de esgoto: efeitos em fertilidade do solo e qualidade da cana de açúcar. Piracicaba, 1995. 165p. Tese (Doutorado) - Escola Superior de Agricultura "Luiz de Queiroz", Universidade de São Paulo.

SOUZA, G.S. Introdução aos modelos de regressão linear e não linear. Brasília: EMBRAPA, SPI, SEA, 1998. 489p.

STEEL, R.G.D.; TORRIE, J.H. Principles and procedures of statistics: with special reference to the biological science. New York: McGraw-Hill, 1960. 481p.

TEDESCO, M.J.; GIANELLO, C.; BISSANI, C.A.; BOHENEN, H.; VOLKWEISS, S.L. Análise de solo, plantas e outros materiais. 2.ed. Porto Alegre: UFRGS, Departamento de Solos, 1995. 174p. (Boletim Técnico, 5).

$\overline{R e c e b i d o ~ e m ~ 20.09 .99 ~}$ 